\title{
REDE DE COMUNICAÇÃO COMO ESTRATÉGIA DE AÇÃO POLÍTICA: ATIVISMO FEMINISTA NO FACEBOOK EM ANÁLISE HISTÓRICA CONTEMPORÂNEA (2013- 2016)
}

\section{COMMUNICATION NETWORK AS A POLICY ACTION STRATEGY: FEMINIST ACTIVISM ON THE FACEBOOK IN CONTEMPORARY HISTORICAL ANALYSIS}

(2013-2016)

\author{
Maria Elisa de Magalhães Santos
}

\begin{abstract}
RESUMO: Um estudo que se concentra na intersecção entre os espaços sociais na internet e as atuações feministas, representam dentro das perspectivas do discurso, um enfrentamento social com a concretude de reflexões às estruturas de poder que ainda repercute no interior dessas e para além dela. O presente artigo tende a corroborar para uma importante análise frente as questões que interrelacionam os diálogos entre a atuação e as possibilidades qual os usos políticos das redes sociais na internet tem fomentado a expansão da vOZ e das permanências femininas em novos espaços. Delimitada temporalmente entre 2013 a 2016, tenho me debruçado frente a quatro grupos, dentre eles feministas e antifeministas atuantes na rede social facebook. À luz da análise do discurso e do estudo analítico referente ao processo cultural histórico, tenho me comprometido a elucidar as contraposições discursivas daquelas que fazem dos usos das redes, ferramentas que disseminam a expansão das desigualdades de gêneros, machismo, sexismo, racismo, homofobia, para àquelas que resinificam esses espaços na busca por uma sociedade mais equânime e plural, por discursos que reestruture as desigualdades de gêneros, o corpo e a identidade da mulher, no intuito de possibilitar debates em campos antes não atuantes pelo feminino. Sendo assim, mesmo minha pesquisa tendo se firmando na contemporaneidade, seu caráter histórico atende-se em raízes regadas no passado. O poder estrutural qual moldaram o corpo, a identidade da mulher, traz para o hoje, significados que são operantes socialmente.
\end{abstract}

PALAVRAS-CHAVES: Rede Social; Facebook; Feminismo; Desigualdade de Gênero.

\begin{abstract}
A study that focuses on the intersection between the social spaces on the internet and the feminist actions, represent within the perspectives of the discourse, a social confrontation with the concreteness of reflections to the structures of power that still resonate within these and beyond. The present article tends to corroborate for an important analysis on the issues that interrelate the dialogues between the performance and the possibilities of which the political uses of the social networks in the internet have fomented the expansion of the voice and the feminine stays in new spaces of reflection. Delimited temporarily between 2013 to 2016, I have been facing six groups, among them feminists and anti-feminists active in the facebook social network. In the light of discourse analysis and analytical study concerning the historical cultural process, I have been committed to elucidating the discursive counterpositions of those that make use of networks, tools that spread the expansion of gender inequalities, machismo, sexism, racism, homophobia, for those who resent these spaces in the quest for a more equitable and plural society, for discourses that restructure gender inequalities, the body and the identity of women, in order to enable debates in fields previously not active by the feminine. Thus, even my research, having established itself in contemporaneity, its historical character is based on roots irrigated in the past. The structural power that shaped the body, the identity of the woman, brings to the present, meanings that are socially operative.
\end{abstract}

KEYWORDS: Social Network; Facebook; Feminism; Gender Inequality.

\section{INTRODUÇÃO}

O grande lócus das conexões entre pessoas atualmente, é representado por uma maciça rede de conectividade deferida pelo uso do computador e suscitada pela internet. Estas redes segundo

\footnotetext{
1 Mestranda - Programa de Pós-Graduação em História/UFG - mariaelisamagalhaes01@gmail.com
} 
Recuero nos aponta que os estudos referente as redes sociais não são de um todo recente, esse enfoque na "sociedade perpassam a ciência durante todo o séc. XX”. Essas mudanças, foram ocasionadas pelos próprios estudiosos dada pela virada do século. Passando no entanto, a demonstrar que os estudos referente a essa área seria visto como um fenômeno constituído através das interações entre as partes, não mais através do todo, como era considerado anterior a este século" (2009, p.17). Em Marteleto, por exemplo, os estudos sobre "redes sociais é tributário", postulando, “pares que são dicotômicos indivíduos/sociedade; ator/estrutura; abordagens subjetivas/objetivistas; enfoque micro ou macro da sociedade" (2001, p. 72).

Nesse sentido, as análises que vislumbram os estudos do conceito de redes sociais,

permitiram a construção de compreensão inovadora da sociedade, que ultrapassa os princípios tradicionais, nos quais o elo social é visto como algo que se estabelece em função dos papéis instituídos e das funções que lhes correspondem .... partir dos vínculos relacionais entre os indivíduos, os quais reforçariam suas capacidades de atuação, compartilhamento, aprendizagem, captação de recursos e mobilização (2010, p. 28).

Nesse contexto, levando em consideração às análises sobre as funcionalidades proporcionadas pelas conexões em rede, o foco do trabalho é pensar justamente os usos políticos tal qual a rede social facebook opera diante a disseminação e permanência da atuação e discurso do movimento feminista na mediação entre o computador e o mundo/pessoas,

1 Fanpages feministas: Think Olga criada em 2013; Vamos Juntas? em 2015. Fanpages antifeministas: Anti-feminista criada em 2013; Orgulho de ser hetero em 2016.De acordo com a autora, "um ator de rede social da internet é designado como bem como, trazer contraposições desses discursos, com àqueles que utilizam desses mesmos usos para propagar uma dinâmica de ódio às lutas engendradas pelo feminismo, que no caso é caracterizado pelo antifeminismo.

Busco, no entanto, fazer uma análise discursiva entre fanpages feministas e antifeminista, criadas no interior do facebook, com o princípio de relacionar as conquista que o movimento feminista teve com a chegada do virtual nas esferas públicas e consequentemente o enfretamento que essas mulheres tiveram para conseguirem um espaço nesse mundo digital ainda muito masculinizado, quais foram esses impasses e como é a medição entre suas lutas e o público que a seguem, em contrapartida, fazer um esboço da construção cultural histórica que levaram e levam a subvalorização das mulheres, intercalando principalmente as premissas pós-modernas e os estudos de gêneros.

Cabe dizer, nesse sentido, que rede social é tudo aquilo que agrupa uma quantidade de pessoas podendo ali perpetuar ações, conversações, representações e pluralidades, etc. É por estes aspectos que me atrevi a pesquisar o facebook, sendo ele um abrangente e proliferador desses princípios, principalmente pela capacidade de criar grupos/fanpages internas, no intuito de se democratizar ainda mais nas categorias conectivas entre sujeitos.

Para tanto, tenho me debruçado frente a quatro $^{1}$ fanpages. Sendo elas minhas fontes de

ferramenta, por exemplo o perfil no facebook ou twitter'. Nesse caso, "essas ferramentas passam a ser os atores, pois considera que a partir desse perfil abra um espaço de interações, lugares de fala, onde expressam elementos de sua 
pesquisa, duas perpetuam as lutas feminista: Think Olga e Vamos Juntas? e as outras o antifeminismo: quais são Anti-feminista e Orgulho de ser hetero. A pesquisa tem recorte temporal delimitado entre 2013 a 2016, pelo fato, que a partir deste período pude perceber um maior crescimento do acesso às conexões em rede em todas as classes sociais e principalmente um salto pertinente das mulheres nos espaços midiáticos, reconfigurando o particular em amostras pluralizadas.

Busco com isso caracterizar, a importância dessas relações para o ativismo das mulheres bem como as representações culturais históricas as quais tem delimitado estruturalmente ser mulher e ser homem. Vou observar este construído, pelos fluxos da História Cultural. Pois é por ela, que vamos nos ater das representações do passado, sempre incumbidos de perguntas/evidências sobre o que levaram e levam a subvalorização feminina.

\section{USOS POLÍTICOS DA REDE} SOCIAL FACEBOOKNO CAMPO DA ATUAÇÃO FEMINISTA: OCUPAR ESPAÇOS

No âmbito da relação computador e ciberespaço, uma rede social é constituída por importantes dois elementos, atores sociais e suas conexões. De acordo com Recuero, a algumas distinções perenes quando trabalhado o "conceito de rede social na internet”. Nesse campo de analise os "atores sociais são denominados como representações ou construções identitárias do ciberespaço", pelo fato que eles não estão envolvidos em uma comunicação física (frente a frente) e sim por meio de uma máquina.

O segundo elemento, não menos importante, são as conexões. Se, por um lado, os atores são representados pelo nós da rede, os que emolduram as relações. As conexões, se destaca pela capacidade de constituir os "laços sociais, que, por sua vez, são formados através da interação social entre os atores". No entanto, um perfil em rede social, sem conexões, não opera na dinâmica da “interação, relação e laços sociais” (RECUERO, 2009, p. 30) constituída nas conjunturas do ciberespaço.

Sendo assim, fazendo um link com o objeto da minha pesquisa, tenho verificado que esses espaços, tem consolidado um momento de pertencimento e enfretamento social para os grupos feministas atuais. A capacidade de interação com o público permite, de acordo com Vieira (2005), vislumbrar, uma relação que abarca tanto a

construção da subjetividade, quanto da linguagem, que é possível antever o papel significativo desempenhado pelos processos midiáticos contemporâneos e, em especial, dos novos agenciamentos da informação, possibilitados pela linguagem da internet ( $p$. 215).

Pois, principalmente, no que compete a pósmodernidade, a noção de sujeito tem-se misturado com o objeto/máquina, na intenção de um espaço cada vez mais digital e proficiente. Esse espaço, necessariamente, remete a linguagem da "matériaprima entre relações e laços sociais" (RECUERO, 2009, p. 30) revogada pela capacidade das interações sociais.

A partir do momento que "demarcamos nossas posições de fala, ocupamos os espaços

são constituídos por meio do objeto (máquina). 
discursivos, categoricamente estamos transgredindo, ultrapassando nossos próprios limites" (Vieira, 2005, p. 216), pluralizando, redirecionando posições e status e nos possibilitando a "contribui para uma política de identidade. Daí o motivo do interesse pelo conceito de resinificar um espaço" para o também pertencimento do "discurso feminino" (p. 217).

Pensando nisso, ao analisarmos a figura feminina pelos traços dados pelo processo cultural histórico $^{2}$, permitimos ver que a estrutura criada envolto de sua imagem, sempre esteve relacionada ao "outro", o não sujeito, que não fala, não questiona, mas obedece, traz uma ligação obscura com a liberdade e os desejos de si. Seu eu no mundo foi e é visto/sentido em segundo plano, nada corresponde à grandes conquistas, sempre enaltecida se estiver um sujeito masculino a frente, 'mostrando' às coordenadas ou simplesmente pelo fato da supremacia qual este foi constituído.

Nesse caso, tenho escolhido trabalhar com essa linha teórica analítica, pelo fato que, de acordo com Pesavento (2012) esta, nos possibilita entrever sempre às "representações antigas, recuperando os registros do passado na sua irredutível especificidade, quando os homens falavam, agiam e construíam representações do mundo estranhas aos nossos códigos e valores" (p. 59). Podendo, nesse sentido, nos mostrar caminhos quais o corpo da mulher foi moldado, significado, estruturado de forma vulnerável e violável.

\footnotetext{
2 Os estudos culturais, por exemplo, avançaram num campo fundamentalmente interdisciplinar (abrangendo inclusive uma parte do que há menos de trinta anos atrás era considerado de interesse exclusivo dos antropólogos) e liderados pelas propostas teóricas de Stuart Hall, propõem uma nova abordagem para uma etnografia das expressões culturais
}

Cabe dizer, nesse contexto, o como foram e são construídas as relações e desigualdades de gênero no meio social. No campo amplo dos estudos/disciplinas dos bancos escolares, gênero nunca é referenciado na sua efêmera abordagem, que é a ideia de poder. Sempre repassado de forma sútil, escorrem entre os dedos aquelas clivagens que são importantes para entender o sujeito homem e o sujeito mulher na sociedade: lugar de fala, poder, subordinação, silenciamento. Segundo Scott (1995), o termo gênero, já no "fim do século XX emerge como uma preocupação teórica, principalmente por parte de feministas contemporâneas", justamente para "sublinhar a incapacidade das teorias existentes para explicar as persistentes desigualdades entre homens e mulheres" (p. 85).

Vendo isso, Scott (1995) nos alimenta de duas definições decisivas para refletirmos sobre gênero. A autora traz convicções no sentido de como foi pensado e construído o sujeito mulher, a partir do distintivo biológico. “(1) o gênero é um elemento constitutivo de relações sociais baseadas nas diferenças percebidas entre os sexos e (2) é uma forma primária de dar significado às relações de poder". Ou seja, o estudo de gênero além de demarcar que nas bases sociais existem uma percepção que desarticula um sexo ao outro (homem/mulher), ele ainda se configura como "um campo primário no interior do qual, ou por meio do qual, o poder é articulado" (p. 86-88).

contemporâneas, refazendo os esquemas vigentes de interpretação de temas como identidade, relações raciais, sexualidade, pertença étnicas, hibridismo cultural, etc. (CARVALHO, 2001, p. 108). 
Nesse mesmo sentido, Maria Rita Kehl (2016), trabalha, assim como Scott (1995) da ideia da figura feminina através do simbólico, este como uma construção cultural e que afeta e dissemina socialmente a mulher. A autora constrói esses sentidos através do que ela chama de "invenção", como se fosse imaginar/enxergar o eu pelo Outro. Um dos indícios que demarca essa construção, a da descoberta de si, é "a primeira definição dada a uma criança, mesmo antes que o feto complete sua evolução... é "menino" ou "menina". Ao enaltecer esses significantes, já molda ali "não apenas uma

diferença anatômica, mas o

pertencimento a um de dois grupos

identitários carregados de significações

imaginárias" (2016, p. 23).

Butler entende no entanto, "que as distinções entre sexo e gênero atende a tese de que, por mais que o sexo pareça intratável em termos biológicos, o gênero é culturalmente construído" (2003, p.24), pois, denota a partir deste, que a criança já nasce com um "manual de instruções, uma fórmula, que designa, lugares, posições, deveres e traços identificatórios (KEHL, 2016, p. 23).

Para além disso, Segato (1998) nos fazem enxergar que estudar gêneros não se resume fixar seu olhar somente nas entrelinhas de registros etnográficos (pensando nesse sentido um estudo dentro do campo da antropologia), temos que pensar para além desse observável, para daí ter a dimensão mais favorável do que consiste a construção dos lugares de fala, poder, patriarcalismo, universalismo e consequentemente ser mais preciso quando perguntado "se existem ou não sociedadesigualitárias" (p. 3). Pois pensar uma sociedade igual (coloco aqui também outros marcadores sociais como: classe e raça), seria uma clivagem errônea no momento que direcionamos nossas falas, analises e questionamentos ao processo histórico qual a mulher foi introduzida, pois para Segato, o estudo das relações de gêneros devem ser entendidas dentro do campo de universo da coerção patriarcal, sob àquelas estruturas que demarcam relações entre posições de hierarquias e dominação simbólica. A partir disso, a autora desenvolve que

O que pode ser observado é o maior ou menor grau de opressão da mulher, o menor ou maior grau de sofrimento, o maior ou menor grau de autodeterminação, o maior o menor grau de oportunidade, de liberdade, etc., mas não a igualdade, pois é do domínio da estrutura, e a estrutura que organiza os símbolos, lhes conferindo sentido, não é da ordem do visível. O poder se revela, às vezes, com infinita sutileza (SEGATO, 1998, p. 3).

\section{FANPAGES FEMINISTA E ANTI-}

\section{FEMISNISTA NA REDE SOCIAL}

\section{FACEBOOK: ANÁLISE DO DISCURSO}

Pensando nessas discussões, e referenciando o quão tem sido importante os estudos de generos na área que abrange a desigualdade sexual e o repensar do sujeito mulher nesses contextos, nos porquês e nas representações sociais qual estas ainda aparecem de um jeito manso, mais inquietante. Procuramos, deste modo, evidenciar aqui, as possibilidades qual suscitaram através da internet a vOZ e ações femininas, de modo revolucionário, persistente e preciso. Espaço que se permanecia obscuro para o seu alcance, mas que agora pouco a pouco ganha cada vez mais visibilidade e consequentemente uma representatividade para as mulheres.

Esse alargamento de fronteiras é chamado 
por Miguel \& Boix (2013) de ciberfeminismo³, pois vai além do que nos foi inserido: "o lar", "o cuidado familiar”, "os afazeres domésticos”. Representou para o movimento feminista e mulheres "um instrumento [que coopta] mudança e liberdade", relacionadas com resistências e proliferação de uma linguagem reconhecidamente feminina em espaços antes silenciadores. Porém, e para além disso, os autores nos faz lembrar, que mesmo o "meio virtual tenha suscitado novas esperanças no sentido de transcender as rígidas e opressivas determinações dos gêneros", é preciso ficarmos atentas para que tudo isso não torne $\mathrm{e} / \mathrm{ou}$ "transforme em uma mera liberdade simbólica" (p. 40).

Nessas condições e destacando as fanpages feministas em contraposição com as antifeministas, tenho consentido, teoricamente através da análise do discurso, uma interposição entre ambas as partes, onde é valido aplicar à inquietação qual Foucault (1999) se coloca. O que há de "mais perigoso no fato de as pessoas falarem e de seus discursos proliferarem indefinidamente?" (p. 8).

Verdadeiramente e pensando junto com o autor, a fala, a linguagem, o discurso nas sociedades, se não a remetemos ou articulamos de forma pluralizada, pode se valer de um motor gerador do que Kehl (2016) chama de "discurso pronto, alienado"4 (p. 18). Penso esse alienado, categoricamente, pelas três fanpages que faz dos

\footnotetext{
${ }^{3}$ Ciberfeminismo (PLANT, 1997; ADAM, 2001; FERNANDEZ, WILDING, 2002; WILDING, 2001) é o termo usado para designar a parte do movimento feminista que se compreende com questões de identidade e os direitos das mulheres no ciberespaço e visualiza as TIC como ferramentas para a emancipação e empoderamento das mulheres (BRUNET; NATANSOHN, 2013, p.164).
}

usos da internet um meio de reproduzir e disseminar o antifeminismo. Pois, o que se encontra em suas postagens, são representações daquele todo moldado sentido do processo cultural qual o corpo da mulher foi estruturado, uma espécie de bolha, onde se vive a mercê dos que detém o poder.

Entre as duas que analiso: Antifeminismo e Orgulho de Ser Hetero, há uma consciência e reverberação de um campo potencialmente reprodutor do ódio, do machismo/sexismo, da homofobia, racismo, de uma agressividade e diminuição da mulher enquanto pessoa. Intersecciona-se entre ambas o que Soihet (2005) desenvolve em sua pesquisa, a questão da zombaria através do cómico, do riso, como uma arma de destruição e persuasão ao Outro, que no caso é a exposição da figura feminina.

Em debate sobre essa teoria do riso, vejamos em Skinner (2002), suas reflexões dentro do ponto vista das concepções filosóficas de Hobbes e a cultura humanista da Renascença, onde se verifica muito do que é reproduzido pelo antifeminismo nas publicações.

Um dos aspectos da teoria do discurso persuasivo, herdada da cultura retórica da antiga Roma pela Renascença, era a crença de que o riso pode ser usado como uma arma potente em debates legais e políticos. ...podemos ser bemsucedidos ao fazer com que nossos adversários dialéticos pareçam ridículos, provocando o riso contra eles, então podemos esperar arruinar sua causa e persuadir nossa audiência a tomar partido por nosso lado ${ }^{5}$ (SKINNER, 2002, p. 9-10)

\footnotetext{
${ }^{4}$ A autora está pensando sexualidade como um conceito central para a psicanálise.

${ }^{5}$ Hobbes põe essa teoria para funcionar de forma devastadora nos últimos capítulos do Leviathan, nos quais ele monta uma sátira selvagem dos estudos escolásticos e da teologia da Igreja Católica, transmitindo seu escárnio e desprezo por meio de uma série de piadas, sarcasmo e outras formas de ridículo (SKINNER, 2002, p. 10).
} 
É de extrema ignorância e violência a forma qual o corpo da mulher é repercutido em imagens e frases nessas páginas. Estereótipos são firmados sobre àquelas que lutam pela causa feminina, feminista, como aspectos da feiura, de uma não higiene pessoal, são arruaceiras, fazem barracos, histéricas, publicações com frases de efeitos como "são feministas pois não conseguem arrumar um macho de verdade", "só querem combater o machismo postando textão no facebook", "feminismo não evita estupro, mulher armada sim", "desigualdade salarial qual falam as feministas é 'mimimi', "feministas são todas gordas", não cuidam do corpo, esse querem como objeto sexual, e consequentemente uma quantidade enorme de apontamentos negativos para quem é a favor da liberação do aborto, com várias hashtags com frases 'precisamos falar sobre aborto', 'aborto é crime'.

É impressionante o quanto a sociedade ainda está crua e cega diante das relações que opera entre liberdade e o corpo feminino. $O$ que mais desassossega são os 'memes' e fantoches colocados envolto das mulheres que é militante à causa do aborto, coloca-as como se fossem assassinas em série, mas em contrapartida, nunca problematizam a quantidade de homens que abandonam suas mulheres ainda gestantes, configurando $\mathrm{O}$ abandono também como reação abortiva masculina. Esses comportamentos, possuem totais reflexos do como é correlacionado as lógicas de criação de um corpo masculino e um corpo feminino.

Isso me lembra de uma passagem dos escritos Nader e Rangel (2014) a partir das considerações de Pomata, Soihet e Priorenão quando nos coloca que esses discursos se

contenta com clivagens entre os sexos, pois dá preferência à identificação dos mecanismos que enunciam e representam a divisão social dos papeis e funções femininos e masculinos, sem os diagnosticar como específicos, mas interessados em explorar a natureza dessas diferenças. Diferenças que imprimem suas marcas nas práticas femininas, mas que encontram lógica nos códigos de comportamento partilhados pelos dois sexos (p. 116).

Exemplos gritantes, mas sem generalizações, demonstram como é a criação entre ambos. Para os meninos uma educação que não são instigados a falar ou expressar os sentimentos, sempre repassar uma imagem de forte, o não chorar, pois "homem que é não chora', não tem aquela fiel cobrança em arrumar uma casa, lavar uma louça, ou até mesmo dobrar a própria cama ao acordar. Enquanto nós mulheres, representam o contrário, desde pequenas ensinadas a lidar com afazeres domésticos, a serem mocinhas educadas, prestativas, não somos estimuladas a fazer coisas que prende nossa atenção ou que demonstre nosso força, principalmente a física, somos proprietárias de uma proteção exacerbada e consequentemente crescemos como seres frágeis e sentimentais.

De fato, certo determinismo histórico-cultural constrói os papéis sexuais mesmo quando desejam opor resistência. Os homens, livres para irem e virem em qualquer direção, tendem a dominar a vida social fora do lar. No interior, a repartição das repartições podem ser variadas, mas, comumente, é legado das mulheres o cuidado do lar. Por essa razão, são tão difíceis e lentas as mudanças sociais referentes à identidade das mulheres, pois cada alteração deve desconstruir processos históricos de séculos de preconceito e de crenças, solidamente estratificados no seio da sociedade (VIEIRA, 2005, p. 223).

Por um outro, e levando com norte o papel dos discursos que interpõe as relações sociais. Temos o papel desempenhado pelas outras fanpages, estas de cunho feminista. Sendo eu uma pesquisadora, leitora e seguidora das questões que envolve mulher, gêneros e feminismo procuro 
como um todo, fazer um panorama sobre o que consiste essas analises teóricas para a construção de uma prática que promova um forma mais pluralizada e equitativa para os sujeitos qual se interseccionam.

A linguagem equaciona um poder imensurável de significados, quando pronunciamos (verbal ou escrita) essa linguagem torna aos ouvidos/olhos do receptor um amontoados de significações que ele ali tenta absorver e procurar onde se encaixar melhor no discurso do outro. Portanto, volto às considerações de Foucault (1999),

O discurso nada mais é do que a reverberação de uma verdade nascendo diante de seus próprios olhos; e, quando tudo pode, enfim, tomar a forma do discurso, quando tudo pode ser dito e o discurso pode ser dito a propósito de tudo, isso se dá porque todas as coisas, tendo manifestado e intercambiado seu sentido, podem voltar à interioridade silenciosa da consciência de si (p. 49).

Por isso a importância de como se fala/escreve, de como se expressa, como é colocado o outro em nossas reflexões, pois o dito, pode significar permanências e/ou reinterpretações. Para quem se fala? Sobre o que se fala? De onde ${ }^{6}$ se fala? Pois o lugar do discurso é um lugar privilegiado ${ }^{7}$.

Neste caso, a minha ideia ao pensar a rede social como campo de estudo, é repensar justamente a proliferação dos sentidos da palavra dita. Vejo entre as fanpages feminista Think Olga e Vamos Juntas?, e não fazendo apologia, uma reabilitação daquilo que por muito tempo tem sido silenciado. Pode parecer aqui, que eu esteja caindo em um grande universo utópico, mas avançamos, não no sentido literal da palavra, avançamos nas

\footnotetext{
${ }^{6}$ Posição social (locutor/receptor) - classe, raça e gênero.
}

conquistas de espaços, mas dentro dessas espaços há uma interrogação, como somos tratadas?

A partir das análises feitas, pude concluir que o dentro ou o fora das paredes do lar, nossos corpos são e estão a mercê de ataques e violação, tanto por olhares, ao toque, aos gemidos, às palavras, ao feminicídio, então a problemática continua, em que medida avançamos?

Vejo que os grupos feministas atuantes no facebook desenvolve para além de um forma de enfretamento social, possiblidades para que a comunidade que as seguem, participem de forma ativa no fortalecimento da causa e na socialização daquilo vivenciado no dia-a-dia. As várias campanhas e projetos idealizados pelas páginas obedecem prioritariamente à exposição de informações no sentido de orientar, 'capacitar' e encorajar mulheres para se posicionarem em certas situações de constrangimentos. É uma forma sutil/imprescindível de questionar as relações e desigualdades de gêneros sob uma abordagem de fácil entendimento e que intercambia sujeitos (mulheres) que possivelmente não tiveram acesso direto a estes estudos (o teórico).

A relação entre feminismo, tecnologia e internet incorporou um discurso estético e político produzido pelo tráfico de signos, artefatos culturais e ressignificações críticas de códigos normativos ligados à feminilidade ...seu uso dá como forma de tradução de termos, ideias e lutas, apostando da eficácia dessa atuação sem considerar os feminismos como consequência de uma consciência prévia e com a finalidade de atrair mais jovens ou ainda deixar mais claro o uso de determinado conceitos, temas e/ou "palavras de ordem" (FERREIRA, 2015, p. 204- 211).

Empoderamento feminino por meio de informações tanto social, no trabalho, sexual e na maternidade; valorização da mulher; melhoria na

\footnotetext{
${ }^{7}$ Referenciando José Jorge de Carvalho em Olhar etnográfico e a voz subalterna (2001).
} 
saúde materna; descriminalização ao aborto; luta pela erradicação à violência contra a mulher; respeito aos direitos humanos; repúdios à discriminação e preconceito racial; implementação do discurso da sororidade entre mulheres e luta contra o machismo institucionalizado (Think Olga, 2013; Vamos Juntas, 2015) ${ }^{8}$. São algumas de suas demandas que condicionam um discurso factual, na esperança de traduzir ações que estão investidas no meio social e virtual. Neste caso, volta-se a pensar em Foucault e nas maneiras como ele trabalha as ordens do discurso, "inquietante em sua realidade material, pronunciada ou escrita; inquietante diante de uma existência transitória, do medo, dos poderes, dos perigos, etc. (p. 8)

\section{CONSIDERAÇÕES FINAIS}

Em consciência desses fatos, acredito muito nos estudos e consequentemente nos avanços quais as mulheres tiveram nos espaços antes denegados. É crescente a ocupação e permanência dessas na transgressão ao lar e a busca por novos horizontes além do que nos foram imposto.

No meio acadêmico estudos sobre gêneros floresceram, porém com barragens que os neutralizam. O cenário que se tem na política e ainda reproduzidos socialmente, fazem com que retrocessos sejam frequentes. De qualquer modo, acreditar que seria fácil quebrar ou acreditaria em processos rápidos na sólida e conveniente estrutura (para os homens) e dilacerante ao feminino, era cair em um grande utopia.

\footnotetext{
${ }^{8}$ Trecho escrito em meu projeto de pesquisa para ingressar no PPGH-Programa de Pós-Graduação em História (2017- 2018) da Universidade Federal de Goiás, intitulado "Redes de Comunicação como estratégia de Ação Política: análise
}

Nos meios virtuais quais opera esta pesquisa, não é diferente, mesmo com todos os esforços do movimento feminista em rede na internet, na produção e "articulação que abarque tanto interesses teóricos e práticas políticas, no abranger de diversas temáticas", apropriando dos "usos das tecnologias da informação e comunicação (TIC's)" para "ao que se tem entendido como empoderamento das mulheres e suas organizações” (FERREIRA, 2015, p.2015). Ainda estamos muito vulneráveis nesse espaço. Uma pesquisa que saiu na Carta Capital a partir de uma campanha realizada pela ONU Mulheres em 2013, cujo título é $A$ desigualdade de gênero está nos seu teclado, mostra como o "preconceito contra as mulheres também invadem a internet". Uma campanha simples, mas de caráter revelador, funcionou no sentido de digitarmos no Google frases do tipo "as mulheres não deveriam" ou "as mulheres precisam" e ver as sugestões de buscas, para compreender qual sentido que a ONU teve ao realizar essa campanha. De acordo com a revista as respostas mais populares para essas frases são do tipo "mulheres não deveriam ter direitos, não deveriam votar, não deveriam trabalhar" ou ainda "mulheres precisam ser colocadas em seus lugares", "precisam ser controladas", "precisam ser disciplinadas", etc (BONIS, 2013).

Desde modo, e ainda segundo a revista, o que essas buscas demonstram é, "quão desiguais são as condições entre homens e mulheres na sociedade. E como essa disparidade reflete na

histórica contemporânea do ativismo feminista no facebook (2013-2016). 
internet e na formação da identidade e dos valores sociais de milhões pessoas", no momento que, ao pesquisarem o pertencimento das mulheres no meio social, ter como resultados, efeitos tão devastadores na formação do corpo e do eu social feminino (BONIS, 2013).

Mas, para além disso, eu na condição de pesquisadora permaneço com a sólida convicção que há a capacidade de avançar. Essas esperanças são tiradas justamente no momento que abro meu perfil no facebook ou escrevo essas páginas e posso experenciar que existe exposto ali mulheres fazendo luta. Transgredir é estar pronta para

\section{REFERÊNCIAS BIBLIOGRÁFICAS}

BUTLER, Judith P.. Problemas de Gênero: feminismo e subversão da identidade. Tradução: Renato Aguiar. 1 ed. Rio de Janeiro: Civilização Brasileira, 2003.

BRUNET, Karla Schuch; NATANSOHN, Graciela. Cultura Digital e Práticas Femininas: LabDbug, relato de uma experiência. In: Graciela Natansohn (Org.). Internet em código feminino: teorias e práticas. Ciudad Autónoma de Buenos Aires. 1a ed. - La Crujía, 2013.

BONIS, Gabriel. A desigualdade de gênero está no seu teclado [internet] / Carta Capital Londres, 2013 [acesso 07/12/2017, às 17:00hrs]. Disponível em:

https://www.cartacapital.com.br/internacio nal/a-desigualdade-de-genero-esta-no-seuteclado- $3392 . \mathrm{html}$.

CARVALHO, José Jorge de. Olhar Etnográfico e a Voz Subalterna. Horizontes Antropológicos, 2001, ano 7, n. 15, p. 107147, Porto Alegre.

FERREIRA, Carolina Branco de Castro. Feminismos Web: linhas de ação e maneiras ultrapassar nossos próprios limites. Me apego nesse sentido, às análises que José Jorge de Carvalho (2001) faz diante do pensamento de Spivak em "discutir a capacidade do subalterno de se representar". Seu olhar para conquanto as premissas da autora revela "teorizar quais são as possibilidades do subalterno de se subjetivar autonomamente" tendo em vista "conquistar um espaço de enunciação, assegurar um lugar de discurso, entendido como sendo o lugar privilegiado nessa batalha por subjetivação equânime” (p. 119-120)

de atuação no debate feminista contemporâneo. Cadernos Pagu, 2015, n.44, pp. 199-228 - Dossiê: Percursos Digitais: corpos, desejos, visibilidade. ISSN 0104-8333.

FOUCAULT, Michel. A Ordem do Discurso. Aula Inaugural no Collège de France, pronunciada em 2 de dezembro de 1970. São Paulo, 5 ed. Edições Loyola, 1999.

KEHL, Maria Rita. Deslocamentos do feminino: a mulher freudiana na passagem para a modernidade. 2 ed. São Paulo: Boitempo, 2016.

MIGUEL, Ana de. BOIX, Montserrat. Os gêneros da rede: os ciberfeminismo. In: Graciela Natansohn (Org.) Internet em código feminino: teorias e práticas. Ciudad Autónoma de Buenos Aires. 1a ed.

- La Crujía, 2013.

MARTELETO, Regina Maria. Análise de Redes Sociais - aplicação nos estudos de transferência da informação. Ciência da Informação. 2001, v. 30, n. 1, pp. 71-81. Brasília. ISSN 0100-1965.

PESAVENTO, Sandra Jatahy. História \& História Cultural. 3 ed. Belo Horizonte: Autêntica, 2012. 
RECUERO, Raquel. Redes Sociais na internet. 1 ed. Porto Alegre: Sulina, 2009. (Coleção Cibercultura).

RANGEL, Lívia A. Silveira; NADER, Maria Beatriz. História das Mulheres e Estudos de Gênero: identidade e relações de poder. In: Maria Beatriz Nader/Lívia de Azevedo Silveira Rangel (Orgs.). Mulheres e Gênero em Debate: representações, poder e ideologia. Vitória: EDUFES, 2014.

SCOTT, Joan. Gênero: uma categoria útil de análise histórica. Educação e Realidade, 20(2): 71-99 jul/dez 1995 (Edição revisada).

SEGATO, Rita Laura. Os percursos do gênero na antropologia e para além dela. Brasília, UNB, 1998. Série Antropologia.

SKINNER, Quentin. Hobbes e a teoria clássica do riso. São Leopoldo/RS: Editora da UNISINOS, 2002.

VIEIRA, Josênia Antunes. A Identidade da Mulher na Modernidade. DELTA Documentação de Estudos em
Linguística Teórica e Aplicada. 2005, vol.21, n.spe, pp. 207-238. ISSN 0102-4450.

\section{FONTE}

Fanpage Anti-Feminismo. 2013 [online] $<$ https://www.facebook.com/antifeminism $\underline{001 / \text { ? } \mathrm{fref}=\mathrm{ts}>}$.

Fanpage Orgulho de ser Hetero.

2016 [online]

$<$ https://www.facebook.com/OrgulhoHetero.Blo $\mathrm{g} /$ ? fref $=\mathrm{ts}>$.

Fanpage Think Olga. 2013 [online] <https://www.facebook.com/thinkolga/?fre $\underline{\mathrm{f}=\mathrm{ts}}>$.

Fanpage

$$
\begin{aligned}
& \text { Vamos } \\
& \text { Juntas? } \\
& 2015 \\
& \text { [online] }
\end{aligned}
$$

$<\underline{\text { https://www.facebook.com/movimentovamosju }}$ ntas/?fref $=$ ts $>$. 